\title{
Effects of membrane structure and operational variables on membrane distillation performance
}

\author{
Vasiliki Karanikola*1, Andrea F. Corral ${ }^{1}$, Hua Jiang ${ }^{1}$, A. Eduardo Sáez ${ }^{1}$, Wendell P. \\ Ela $^{1}$ \& Robert G. Arnold ${ }^{1}$ \\ ${ }^{1}$ Department of Chemical and Environmental Engineering, The University of Arizona, \\ 1133 E. James E. Rogers Way, Harshbarger 108, Tucson, AZ 85721 \\ Email: vkaranik@email.arizona.edu Phone: (520) 626-9323
}

\begin{abstract}
A bench-scale, sweeping gas, flat-sheet Membrane Distillation (MD) unit was used to assess the importance of membrane architecture and operational variables to distillate production rate. Sweeping gas membrane distillation (SGMD) was simulated for various membrane characteristics (material, pore size, porosity and thickness), spacer dimensions and operating conditions (influent brine temperature, sweep gas flow rate and brine flow rate) based on coupled mass and energy balances. Model calibration was carried out using four membranes that differed in terms of material selection, effective pore size, thickness and porosity. Membrane tortuosity was the lone fitting parameter. Distillate fluxes and temperature profiles from experiments matched simulations over a wide range of operating conditions. Limitations to distillate production were then investigated via simulations, noting implications for MD design and operation. Under the majority of conditions investigated, membrane resistance to mass transport provided the primary limitation to water purification rate. The nominal or effective membrane pore size and the lumped parameter $\varepsilon / \delta \tau$ (porosity divided by the product of membrane tortuosity and thickness) were primary determinants of membrane resistance to mass transport. Resistance to Knudsen diffusion dominated membrane resistance at pore diameters $<0.3 \mu \mathrm{m}$. At larger pore sizes, a combination of resistances to intra-pore molecular diffusion and convection across the gas-phase boundary layer determined mass transport resistance. Findings are restricted to the module design flow regimes considered in the modeling effort. Nevertheless, the value of performance simulation to membrane distillation design and operation is well illustrated.
\end{abstract}

Key Words: Sweeping Gas Membrane Distillation; Desalination; Flat Sheet Membrane; Heat and Mass Transfer 


\section{Introduction}

2 Membrane distillation (MD) is a thermally driven desalination process in which vapor diffuses

3 through a porous membrane with at least one side in direct contact with the process liquids $[1,2]$.

4 Transmembrane transport depends on a gradient in the partial pressure of water vapor in the

5 membrane pores that is maintained by raising the temperature of the liquid feed stream and

6 continuously removing water vapor from the permeate side of the membrane. A hydrophobic

7 porous membrane retains the feed solution via surface tension, allowing water to cross the

8 membrane as a vapor [3]. Pore wetting does not occur if the transmembrane pressure differential

9 is lower than the liquid entry pressure (LEP), which is a function of pore size and the contact

10 angle of the membrane material $[4,5]$. MD enjoys several advantages over other desalination

11 processes. MD operates at lower temperatures than conventional distillation/evaporation

12 processes and lower pressures than reverse osmosis. MD produces $\sim 100 \%$ theoretical rejection

13 of ions [6]. Because vapor pressure is reasonably insensitive to ionic strength, permeate

14 production and energy requirements are weakly dependent on brine salinity. However, a

15 significant process limitation lies in the energy required to operate $\mathrm{MD}$, which is dominated by

16 the energy necessary to evaporate water. The latent heat of water evaporation, $\Delta \mathrm{H}$, equals 2260

$17 \mathrm{~kJ} / \mathrm{kg}$ or $628 \mathrm{kWh} / \mathrm{m}^{3}$. At 10 cents per $\mathrm{kWh}$, the energy cost to evaporate water is $\$ 0.24$ per

18 gallon, suggesting that recovery of energy or use of waste heat is essential to MD

19 competitiveness in many situations.

20 In SGMD, a flowing gas collects water vapor on the permeate side before exiting the module,

21 allowing pure water to be condensed externally. In addition to salt separation, SGMD has been

22 used to remove volatile solutes from aqueous solutions [7, 8]. Advantages specific to SGMD

23 include relatively low heat loss through the membrane, low resistance to mass transfer and a high 
24 driving force for transmembrane transport that is maintained by continuous removal of vapor

25 from the permeate side of the membrane [9]. Although SGMD offers the possibility of energy

26 recovery through internal recondensation, in general SGMD systems require an external

27 condenser and an air blower [10].

28 Mathematical modeling of SGMD based on coupled heat and mass balances has been used to

29 determine the sensitivity of permeate flux to variations in operational parameters $[7,10,11]$.

30 Charfi et al. (2010) performed a 2-D numerical simulation of SGMD using the Darcy-

31 Brinkman-Forcheimer representation of momentum transport [7]. Experiment and prediction

32 were in good agreement [7]. More recently, Karanikola et al. (2015) developed a model for

33 SGMD using hollow-fiber modules [11]. The model was based on discretized forms of heat and

34 mass balances in the membrane module, and it satisfactorily predicted permeate production rates,

35 as well as temperature profiles through the module. In the mentioned studies, effects arising from

36 mesh spacers were not considered.

37 Previous modeling and experimental efforts have not placed extensive effort on the assessment

38 of effects of membrane structure on permeate production. In this work, flat sheet SGMD was

39 modeled throughout the practical range of relevant physical membrane characteristics (pore size,

40 thickness, porosity and tortuosity), incorporating the effects of spacers on heat and mass transfer.

41 The validated model was used to explore the sensitivity of water production rate to membrane

42 characteristics over a broad range of system operational variables, i.e., brine temperature and

43 flow rate and sweep gas flow rate. Results are used to identify physical and operational

44 limitations to rates of water purification via SGMD. 
48 Membrane specifications are summarized in Table 1. All membranes were from Millipore.

49 Except for a dual layer polytetrafluorethylene (PTFE) membrane supported by a polypropylene

50 (PP) layer, all were monolayer polyvinylidene fluoride (PVDF) membranes. SEM micrographs

51 are provided (Figure 1).

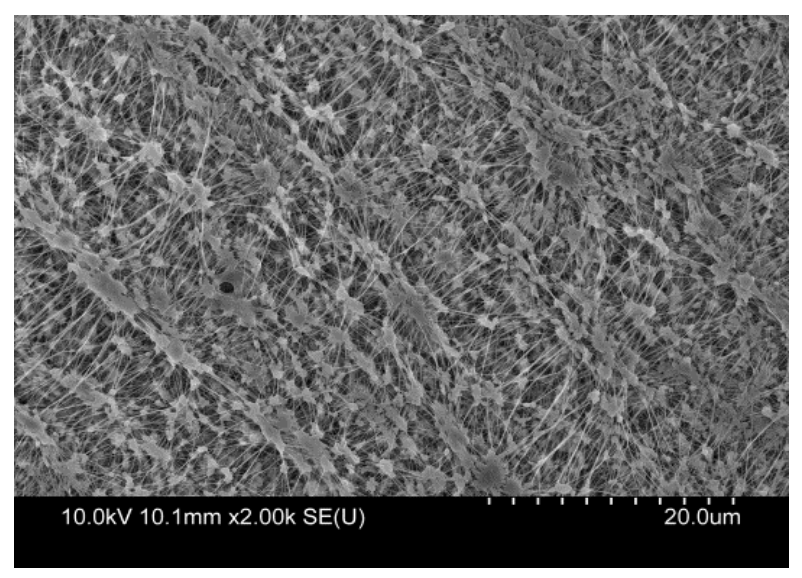

Top view of PTFE membrane $\mathrm{d}_{\mathrm{p}}=0.45 \mu \mathrm{m}$

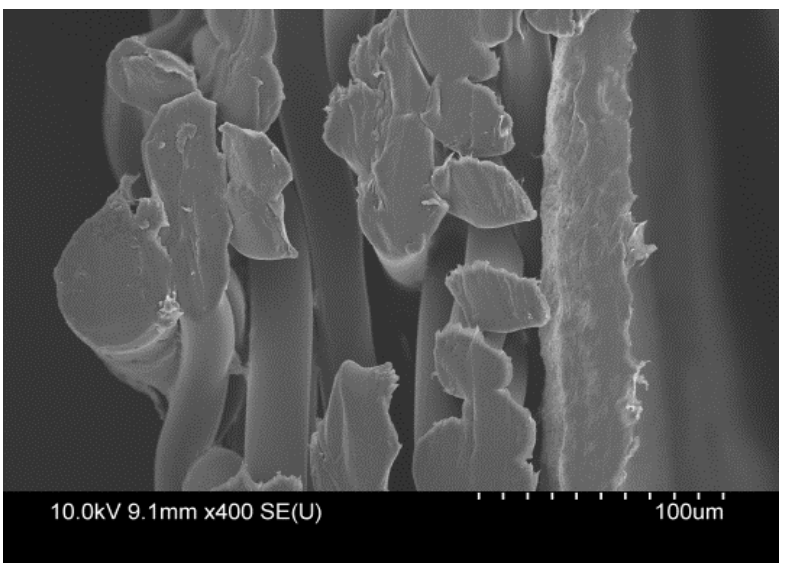

Cross section of PTFE, $30 \mu \mathrm{m}$ membrane active layer and $130 \mu \mathrm{m}$ PP support layer

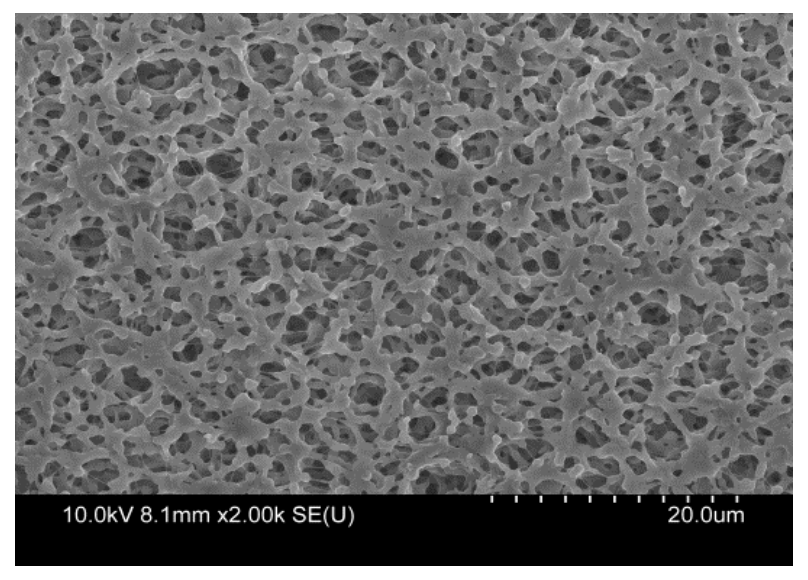

Top view of PVDF membrane $d_{p}=0.45 \mu \mathrm{m}$

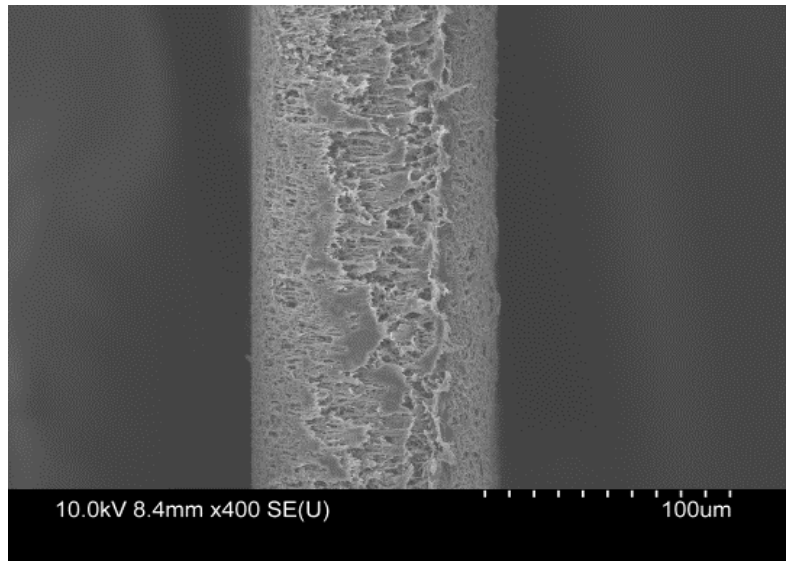

Cross section of PVDF membrane, $110 \mu \mathrm{m}$ uniform membrane active layer

Figure 1. Scanning electron micrographs of PVDF and PTFE membranes. The dual layer character of the PTFE membrane is clearly seen (lower left).

55 In the SGMD experimental setup (Figure 2), brine was heated and recirculated at velocities from

$560.024 \mathrm{~m} / \mathrm{s}$ to $0.11 \mathrm{~m} / \mathrm{s}$ on the brine side of the hydrophobic porous membrane. Vapor pressure at 
57 the brine/air interface was manipulated by varying the influent brine temperature. A plate and

58 frame module with thermocouple monitoring was fabricated for bench-scale experiments

59 (Figure 3).

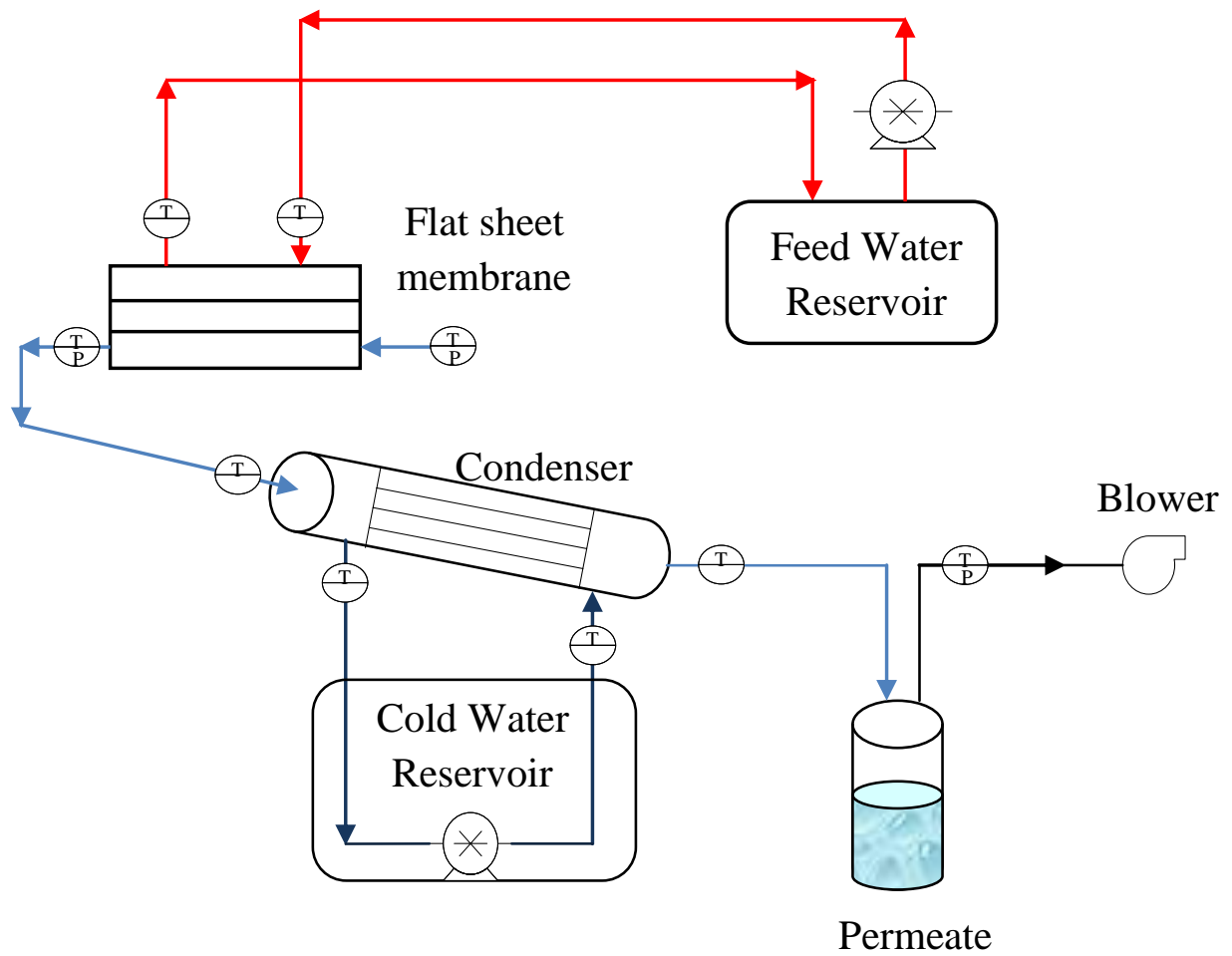

60 Figure 2. Lab-scale experimental set up. Fluid flow pathways include the high-temperature

61 brine/membrane loop (red) and the sweep gas pathway (blue). Condensate was collected in the permeate tank.

63

64 The module consisted of two Deldrin plates $(21 \mathrm{~cm} \times 16.5 \mathrm{~cm} \times 3.8 \mathrm{~cm}$ each $)$. Deldrin was

65 selected for its low thermal conductivity $\left(\lambda_{\mathrm{D}}=0.33 \mathrm{~W} / \mathrm{m} \cdot \mathrm{K}\right)$ compared to stainless steel

66 (common material for plate and frame modules) to minimize heat loss and amenability to

67 computer controlled 3-D milling. Each plate had a milled chamber with dimensions $14.5 \mathrm{~cm} \times$

$689.5 \mathrm{~cm} \times 0.15 \mathrm{~cm}$. The brine flow passed through one chamber, and air was swept through the

69 other. The membrane that separated the two chambers had a working area of $0.015 \mathrm{~m}^{2} . \mathrm{Mesh}^{2}$ 
70 spacers were placed on both sides of the membrane for support and fluid mixing. Spacer

71 characteristics are presented in Table 2.

72 Table 1. Membrane Specifications

\begin{tabular}{|c|c|c|c|c|}
\hline Membrane Specifications & $\begin{array}{c}\text { Membrane } \\
\text { A }\end{array}$ & $\begin{array}{c}\text { Membrane } \\
\text { B }\end{array}$ & $\begin{array}{c}\text { Membrane } \\
\text { C }\end{array}$ & $\begin{array}{c}\text { Membrane } \\
\text { D }\end{array}$ \\
\hline Membrane material $^{\mathrm{a}}[--]$ & $\mathrm{PVDF}^{\mathrm{b}}$ & $\mathrm{PVDF}^{\mathrm{c}}$ & $\mathrm{PTFE}^{\mathrm{P}} \mathrm{PP}^{\mathrm{b}}$ & $\mathrm{PVDF}^{\mathrm{c}}$ \\
\hline Pore Size $^{a} d_{p}[\mu m]$ & 0.22 & 0.45 & 0.45 & 0.65 \\
\hline Thickness $\delta[\mu \mathrm{m}]$ & 125 & 110 & $30 / 130$ & 115 \\
\hline Porosity $^{\mathrm{a}} \varepsilon[\%]$ & 75 & 70 & 75 & 70 \\
\hline Thermal conductivity ${ }^{\mathrm{a}} \lambda_{\mathrm{m}}[\mathrm{W} / \mathrm{m} \cdot \mathrm{K}]$ & 0.18 & 0.18 & $0.25 / 0.17$ & 0.18 \\
\hline Contact Angle $\left[{ }^{\circ}\right]$ & 109 & 150 & 120 & 150 \\
\hline Tortuosity $^{\mathrm{d}} \tau[-]$ & 2.5 & 2 & $3.4 / 1.7$ & 1.8 \\
\hline $\begin{array}{l}\text { Membrane mass transfer coefficient } \mathrm{t}^{\mathrm{e}} \\
\mathrm{k}_{\mathrm{m}}[\mathrm{m} / \mathrm{s}]\end{array}$ & 0.042 & 0.070 & 0.075 & 0.054 \\
\hline
\end{tabular}

73 a Manufacturer's data (Millipore)

74 b Hydrophobic

75 c SuperHydrophobic

76 d Fitted parameter

77 e Calculated, see text.

79 In previous plate and frame studies [12, 13], air entered the permeate chamber via (i) a single

80 point of entry (orifice) at one end of the module, or (ii) a 2-way distributor located in the middle

81 of the chamber that contained a series of small orifices along its length. These geometries may

82 have provided non-uniform flow conditions in the sweep gas over much of the air-side module

83 chamber with attendant challenges for mathematical simulation. Consequently, the air-side

84 chamber was designed so that air entered from a channel on one end and exited to a second

85 channel at the other end in order to encourage uniform flow conditions across the chamber

86 (Figure 3). 


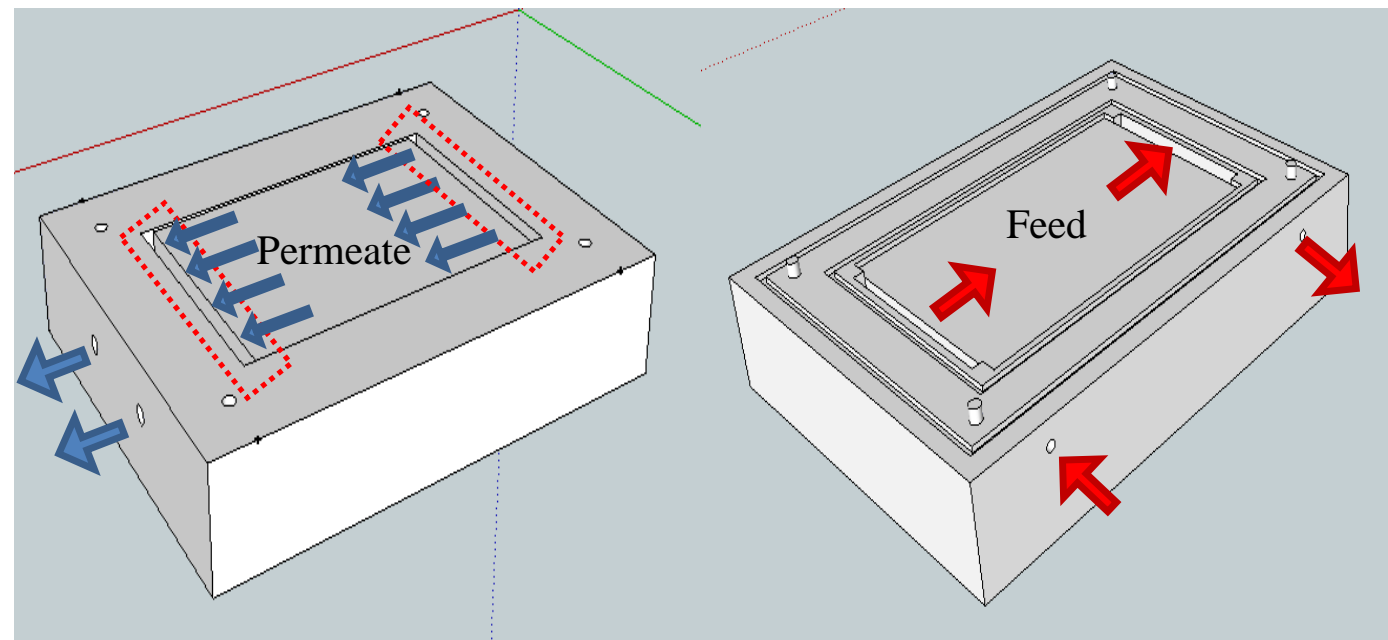

87 Figure 3. - Flat sheet module. Left: permeate side bottom plate. Arrows denote the direction of 88 the sweep air flow and red dashed line denotes the inlet distribution and outlet channels. Right: air side top plate. Arrows show the direction of the air flow. Each side has an engraved chamber of $\mathrm{L} 14.5 \mathrm{~cm} \times \mathrm{W} 9.5 \mathrm{~cm} \times \mathrm{D} 0.15 \mathrm{~cm}$.

92 Sweep air was pulled through the module chamber by a blower (Gast, ShopVac, 0.5 peak hp)

93 countercurrent to the brine flow. The water content in air leaving the module was determined

94 using the permeate collection and gas flow rates, assuming that the condenser exit gas was

95 saturated at the condenser exit temperature. Cold water $\left(15^{\circ} \mathrm{C}\right)$ was provided continuously at 1.5

$96 \mathrm{~L} / \mathrm{min}$ to the condenser (Model \# AB-404-85098, Thermal Transfer Products, interfacial area $\left.97 \quad 0.57 \mathrm{~m}^{2}\right)$.

98 Thermocouples were installed at the inlet and outlet of the module (two on both the water and air 99 sides), the inlet and outlet of the condenser (two on each side) and the permeate collection tank.

100 Rotameters were present in the brine and air loops. Brine flow was regulated at the module 101 entrance, and air flow was controlled after the permeate tank. Vacuum pressure gauges were 102 placed in the air loop before and after the module, before the condenser and after the permeate 103 tank. 
104 The performance of the system was examined by varying the brine feed temperature and flow 105 rate and the flow of sweeping gas. The effect of membrane structure was then established using

106 the four membrane types described (Table 1) and extended via process simulation. Dependent

107 variables included the flowrate and quality of permeate and pressures/temperatures at the points

108 indicated. An Omega USB-4718 portable data acquisition module was used to translate the K-

109 type thermocouple signals and transmit data to the computer. The nine thermocouples reported to

110 a single data hub. The brine solution consisted of $0.05 \mathrm{wt} \% \mathrm{NaCl}$ (Fisher Scientific) in Milli-Q

111 (Merck Millipore) water. $\mathrm{NaCl}$ concentrations were calculated from measured electrical

112 conductivity in the feed and permeate solutions using a benchtop thermal conductivity meter

113 (inoLab® Cond Level 2).

114 Table 2. Spacer Specifications. Geometries illustrated in Figure 5.

\begin{tabular}{ccccc}
\hline Spacer Specifications & $\begin{array}{c}\text { Mesh } \\
\text { Angle } \\
\boldsymbol{\theta}\left[^{\circ}\right]^{\mathbf{a}}\end{array}$ & $\begin{array}{c}\text { Spacer Filament } \\
\text { Diameter } \\
\mathbf{d}_{\mathbf{f}}[\mathbf{m m}]^{\mathbf{a}}\end{array}$ & $\begin{array}{c}\text { Spacer } \\
\begin{array}{c}\text { Mesh Size } \\
\mathbf{l}_{\mathbf{m}}[\mathbf{m m}]^{\mathbf{a}}\end{array}\end{array}$ & $\begin{array}{c}\text { Thickness } \\
\mathbf{H}[\mathbf{m m}]^{\mathbf{a}}\end{array}$ \\
\hline $\begin{array}{c}\text { Feed Side Spacer } \\
\text { Permeate Air Side Spacer }\end{array}$ & 90 & 0.47 & 2.76 & 1.19 \\
\hline Measured & 90 & 1 & 4 & 1.2 \\
\hline
\end{tabular}

115 a Measured

\section{Modeling Approach}

118 A previously developed model for a hollow fiber SGMD module based on coupled energy and

119 mass balances [11] was modified to simulate flat sheet module performance. The discretized

120 mass and energy balances support calculation of the molar rate of water vapor transfer from

121 liquid to gas and the partial pressure of water on the air side. If the partial pressure of water 122 exceeds the vapor pressure at the gas-phase temperature, water condenses inside the module.

123 However, due to the relatively short gas-phase path length in the bench-scale module, 
124 recondensation in the module was neither predicted nor observed under the experimental

125 conditions used (see below).

126 Control volumes for mass and energy balances consisted of finite sections through either the

127 liquid or the gas phase contents of the module (Figure 4). Full development of heat and energy

128 balances was provided previously [11]. Only details specific to the plate-and-frame

129 configuration are provided here.

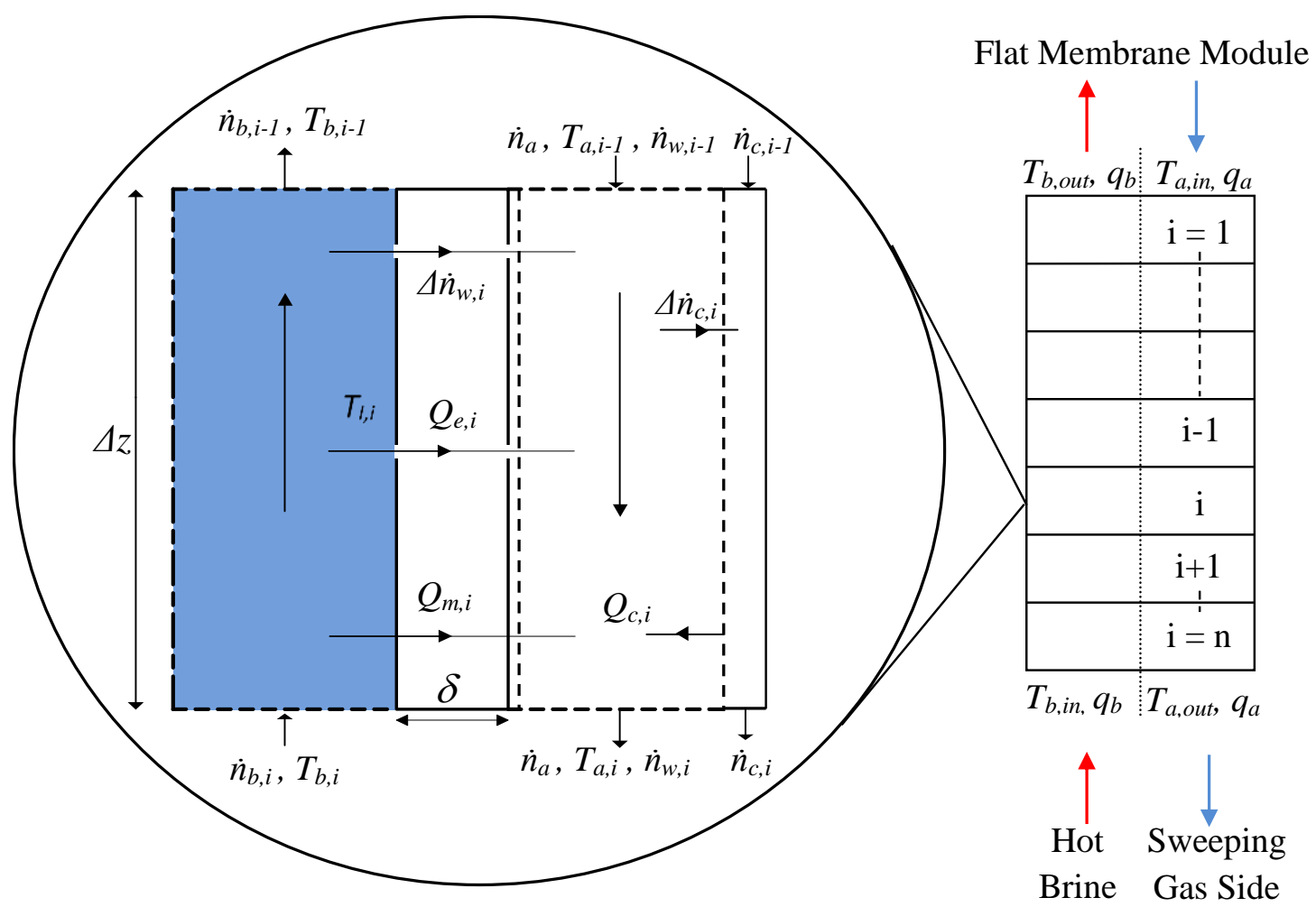

131 Figure 4. A magnified module section, $\Delta z$ in thickness, consisting of a single membrane section to illustrate the basis of the local mass and energy balances. The right side dashed square denotes the control volume for local mass balance. $\Delta \dot{n}_{w, i}$ is the molar water vapor rate of transport through the membrane, $Q_{m, i}$ is the rate of energy transfer through the membrane, $Q_{c, i}$ is rate at which heat is released via condensation of the water vapor on the air side, $Q_{e, i}$ is the rate at which heat is lost from the liquid stream due to evaporation, $\Delta \dot{n}_{c, i}$ is the molar water vapor condensation rate in the section, $T_{a}$ is the temperature of the air, $T_{b}$ is the temperature of the brine, $T_{I, i}$ is the interfacial membrane pore temperature of the brine, $\dot{n}_{c}$ is the molar water 139 condensation rate, $\dot{n}_{w}$ is the molar water rate of vapor at each section, $\dot{n}_{b}$ is the molar brine rate, 
$140 \quad \dot{n}_{a}$ is the molar air rate, $q_{a}$ is the volumetric flowrate of air and $q_{b}$ is the volumetric flowrate of

143 The driving force for mass transfer across the membrane was the difference between the vapor

144 pressure of water at the brine/gas interface in the membrane pores and the local partial pressure

145 of water vapor in the bulk sweeping gas. Mass transfer resistances included the membrane

146 resistance (due to molecular diffusion and/or Knudsen diffusion) and boundary layer resistance

147 on the gas (permeate) side. The driving force for energy transfer to the liquid/gas interface was

148 the difference between bulk brine temperature and the brine temperature at the interface.

149 Resistance was provided by the brine-side thermal boundary layer. A second energy balance

150 was necessary to account for energy transfer from the brine/gas interface into the sweeping gas.

151 In that case, the driving force was the difference between interfacial and bulk gas-phase

152 temperatures, and resistance was provided by the membrane material and membrane pores (in

153 parallel) and the gas-phase thermal boundary layer. For mathematical details, see [11] and SI.

\section{Resistance to mass transport.}

156 Water mass balances in each section of the module have been presented elsewhere [11]. To

157 assess the potential effect of membrane structure on water production during SGMD, it is 158 necessary to summarize relationships governing resistance to trans-membrane mass transfer. The 159 trans-membrane flux of water vapor through membrane pores in the ith section of the discretized 160 module (Figure 4) was represented by $J_{\mathrm{i}}\left(\mathrm{mol} / \mathrm{m}^{2} \mathrm{~s}\right)$, where

$$
J_{i}=\frac{k_{t o t}}{R T}\left(P_{I, i}-P_{w, i}\right)
$$


161 In this equation, $k_{t o t}(\mathrm{~m} / \mathrm{s})$ is the overall mass transfer coefficient of water vapor, $R$ is the gas law

162 constant $(8.314 \mathrm{~J} / \mathrm{mol} \mathrm{K}), T(\mathrm{~K})$ is the average temperature between the brine and air streams at

163 each section of the module, $P_{I, i}(\mathrm{~atm})$ is the vapor pressure calculated from Antoine's equation

164 using the local interfacial temperature $\left(T_{I, i}\right)$ at the membrane pore entrance and $P_{w, i}(\mathrm{~atm})$ is the

165 partial pressure of water vapor in the sweep gas [11]. Equation 1 shows that the driving force

166 for water transport through the membrane is the difference between the local vapor pressure of

167 the brine and the local partial pressure of water vapor on the air permeate side.

168 The overall mass transfer coefficient, $k_{t o t}$, is related to mass transfer resistances in the system

169 [14]. Water transport resistance on the brine side of the membrane was neglected due to the

170 insignificant variations of the water concentration on the brine side (effects of concentration

171 polarization were determined negligible) and the contribution of viscous transport through the

172 membrane pores to transport was insignificant compared to the other transport mechanisms [11].

$$
R_{\text {tot }}=\frac{1}{k_{\text {tot }}}=R_{m}+R_{a}=R_{m}+\frac{1}{k_{a}}
$$

173 where $R_{m}$ is the resistance to water vapor transport across the membrane, $R_{a}$ is the resistance to

174 mass transport in the air-side boundary layer, and $k_{a}(\mathrm{~m} / \mathrm{s})$ is the mass transfer coefficient in the

175 air-side boundary layer. $R_{m}$ was represented as

$$
R_{m}=\frac{\delta}{D_{e f f}}
$$

176 where $\delta(\mathrm{m})$ is the thickness of the membrane and $D_{\text {eff }}\left(\mathrm{m}^{2} / \mathrm{s}\right)$ is the effective diffusivity of water 177 vapor in the membrane.

178 The effective diffusivity, $D_{\text {eff }}$, in a porous membrane is proportional to $\varepsilon$, the membrane porosity, 179 and inversely proportional to $\tau$, the effective tortuosity of pathways through the membrane, 


$$
D_{e f f}=\frac{\varepsilon}{\tau} D
$$

180 Porosity was obtained from membrane specifications, and tortuosity was treated as an adjustable

181 parameter. $D$ is the diffusivity of the vapor through the membrane, which is represented as the

182 combination of Knudsen and molecular diffusion contributions; that is,

$$
D^{-1}=D_{m o l}^{-1}+D_{K n}^{-1}
$$

183 in which the molecular diffusivity, $D_{m o l}\left(\mathrm{~m}^{2} / \mathrm{s}\right)$ was estimated from the relation presented by [15]:

$$
D_{m o l}=\frac{0.926}{10^{6} P_{t o t}}\left(\frac{T^{2.5}}{T+245}\right)
$$

184 where $P_{\text {tot }}$ is the total local pressure $(\mathrm{kPa})$ and $T(\mathrm{~K})$ is the temperature of the feed side solution.

185 The Knudsen diffusivity, $D_{K n}\left(\mathrm{~m}^{2} / \mathrm{s}\right)$, was obtained from [16] as

$$
D_{K n}=\frac{2}{3} r_{p}\left(\frac{8 R T}{\pi m_{w}}\right)^{1 / 2}
$$

186 where $r_{p}$ is the pore radius $(\mathrm{m}), T$ is the average temperature between the brine and air streams at 187 each section of the module $(\mathrm{K})$, and $m_{w}$ is the molecular mass of water $(\mathrm{kg} / \mathrm{mol})$.

188 For the dual-layered membrane (membrane plus support; membrane $\mathbf{C}$ in Table $\mathbf{1}$ ), $R_{m}$ was 189 calculated as the sum of resistance to mass transport of the active membrane layer $\left(\mathrm{R}_{\mathrm{m} 1}\right)$ and the 190 resistance due to molecular diffusion in the support layer $\left(\mathrm{R}_{\mathrm{m} 2}\right)$.

$$
R_{m}=R_{m 1}+R_{m 2}
$$

192 In the flat-plate apparatus, feed-side and permeate-side spacers were utilized for membrane 193 support and improvement of mass/heat transfer characteristics. Spacers tend to reduce the 194 boundary layer resistance to heat and mass transfer on the air or permeate side of the membrane 
195 and resistance to heat transfer on the brine side. Values of the mass transfer coefficient on the

196 permeate side, $k_{a}(\mathrm{~m} / \mathrm{s})$, are related to the Sherwood number by

$$
k_{a}=\frac{D_{m o l} S h}{d_{h s}}
$$

197 The hydrodynamic diameter for a single rhombus of the mesh spacer (Figure 5), $d_{h s}(\mathrm{~m})$, was 198 calculated per [17],

$$
d_{h s}=\frac{4 \varphi d_{f} H}{2 d_{f}+4(1-\varphi) H}
$$

199 where $\mathrm{d}_{f}(\mathrm{~m})$ is the diameter of one filament of the spacer, $H(\mathrm{~m})$ is the thickness of the spacer 200 and $\varphi$ is the spacer voidage, calculated from

$$
\varphi=1-\left(\frac{\pi d_{f}^{2}}{2 l_{m} H \sin \theta}\right)
$$

201 where $l_{m}(\mathrm{~m})$ is the mesh size, and $\theta\left(^{\circ}\right)$ is the orientation angle of the mesh (Figure 5). The 202 characteristics of spacers used here were presented in Table 2.

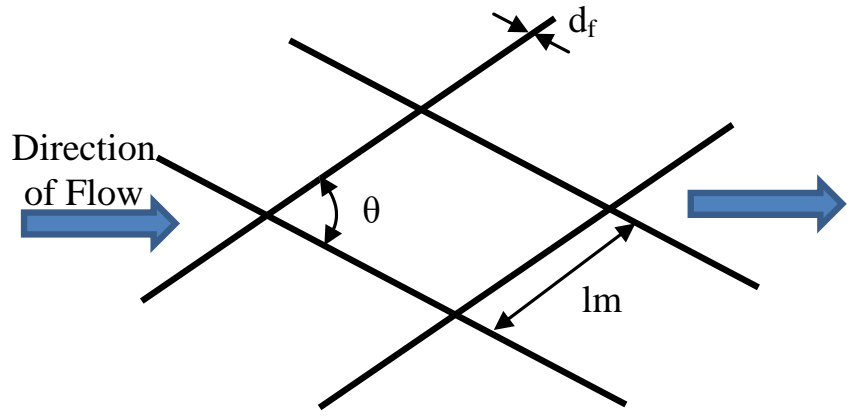

(a) Top View

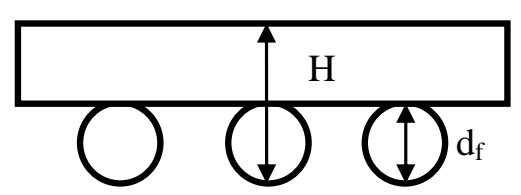

(b) Cross Section View

204 Figure 5. Spacer Views. Spacer dimensions/properties were as illustrated.

206 The Sherwood number on the air side was estimated from an empirical relation that is specific 207 for laminar flow [18] 


$$
S h=0.664 k_{d c} \operatorname{Re}^{0.5} S c^{0.33}\left(\frac{d_{h s}}{l_{m}}\right)^{0.5}
$$

208 where $k_{d c}$ is a correction factor for spacer geometry that was calculated from [17]

$$
k_{d c}=1.654\left(\frac{d_{f}}{H}\right)^{-0.039} \varphi^{0.75}\left[\sin \left(\frac{\theta}{2}\right)\right]^{0.086}
$$

209

$210 \quad$ The Reynolds number is defined by

$$
R e=\frac{u_{a} d_{h s} \rho_{v}}{\mu_{v}}
$$

211 where $u_{a}$ is the sweeping gas approach velocity $(\mathrm{m} / \mathrm{s})$, calculated by dividing the volumetric air

212 flow rate by the cross-sectional area of the air side chamber of the module; $\rho_{v}$ is the density of

213 the gas phase $\left(\mathrm{kg} / \mathrm{m}^{3}\right)$; and $\mu_{v}$ is the viscosity of the gas (Pa s) on the permeate side. Reynolds

214 numbers on both the air and feed sides of the membrane were always within the laminar regime.

215 The Schmidt number was obtained from:

$$
S c=\frac{\mu_{v}}{\rho_{v} D_{m o l}}
$$

216 From the foregoing, it is apparent that the internal membrane resistance has two components-

217 resistance to Knudsen diffusion, which is proportional to $\delta \tau / \varepsilon$ and $\mathrm{d}_{\mathrm{p}}{ }^{-1 / 2}$, and resistance to

218 molecular diffusion, which is proportional to $\delta \tau / \varepsilon$ but independent of pore size. At constant

219 temperature and pressure, the gas-phase boundary layer resistance is proportional to $\mathrm{u}_{\mathrm{a}}^{-1 / 2}$.

220 Component resistances to trans-membrane flow of water vapor are additive. 
226 The contributors to energy balances in each section of the module (Figure 4) were heats of 227 evaporation/condensation and the transmembrane transfer of heat from the hot brine to the cooler 228 gas phase.

229 Heat balances in the brine and air-side sections were used to calculate temperatures as a function 230 of position in the brine and air streams. The energy balance on the brine side for the ith section 231 (Figure 4) states that the energy lost by the brine is equal to the energy transferred to the 232 membrane surface,

$$
\dot{n}_{b} c_{p, b}\left(T_{b, i}-T_{b, i-1}\right)=h_{w} A_{i}\left(T_{b, i}-T_{I, i}\right)
$$

233 where $\dot{n}_{b}(\mathrm{~mol} / \mathrm{s})$ is the molar brine flow, $c_{p, b}(\mathrm{~J} / \mathrm{mol} \mathrm{K})$ is the specific heat of the brine, $T_{b, i}$ and $234 T_{b, i-1}(\mathrm{~K})$ are the inlet and outlet brine temperatures in section $i$, respectively, $h_{w}\left(\mathrm{~W} / \mathrm{K} \mathrm{m}{ }^{2}\right)$ is the 235 brine-side heat transfer coefficient (see below), and $A_{i}\left(\mathrm{~m}^{2}\right)$ is the area of the membrane section.

236 The energy transferred from the membrane interface to and through the membrane is described 237 by:

$$
h_{w} A_{i}\left(T_{b, i}-T_{I, i}\right)=Q_{m, i}+Q_{e, i}
$$

238 Where $Q_{m, i}(\mathrm{~W})$ is the rate of heat transfer across the membrane section and is given by:

$$
Q_{m, i}=h_{t o t} A_{i}\left(T_{I, i}-T_{a, i}\right)
$$

239 where $T_{a, i}$ is the section's air temperature, $h_{t o t}\left(\mathrm{~W} / \mathrm{K} \mathrm{m}^{2}\right)$ is the overall transmembrane heat 240 transfer coefficient from the membrane to the air side (see below). In equation 7 ,

$$
Q_{e, i}=\Delta \dot{n}_{w, i} \Delta H_{v, w}
$$


241 in which $Q_{e, i}(\mathrm{~W})$ is the rate at which heat is provided to evaporate liquid water from the brine

242 stream, $\Delta \dot{n}_{w, i}(\mathrm{~mol} / \mathrm{s})$ is the rate of vapor or permeate production and $\Delta H_{v, w}(\mathrm{~J} / \mathrm{mol})$ is the latent

243 heat of vaporization of water.

244 The thermal energy balance on the air side is given by

$$
\dot{n}_{a} c_{p, a}\left(T_{a, i}-T_{a, i-1}\right)+\dot{n}_{w, i-1} c_{p, v}\left(T_{a, i}-T_{a, i-1}\right)+\Delta \dot{n}_{w, i} c_{p, v}\left(T_{I, i}-T_{a, i}\right)=Q_{m, i}+Q_{c, i}
$$

245 where $c_{p, a}(\mathrm{~J} / \mathrm{mol} \mathrm{K})$ is the gas-phase specific heat, $T_{a, i}$ and $T_{a, i-1}(\mathrm{~K})$ are the inlet and outlet gas-

246 phase temperatures at section $i$, and $c_{p, v}(\mathrm{~J} / \mathrm{mol} \mathrm{K})$ is the heat capacity of water vapor.

$247 Q_{c, i}(\mathrm{~W})$ is the energy released by condensation of water vapor in the section

$$
Q_{c, i}=\Delta H_{v, w} \Delta \dot{n}_{c, i}
$$

248 where $\Delta \dot{n}_{c, i}(\mathrm{~mol} / \mathrm{s})$ is the rate of vapor condensation in the air stream..

249 The membrane heat transport coefficient, $h_{t o t}$, is expressed in terms of a sum of heat transfer 250 resistances,

$$
\frac{1}{h_{t o t}}=\frac{1}{h_{a}}+\frac{\delta}{\lambda_{e f f}}
$$

251 where $h_{a}\left(\mathrm{~W} / \mathrm{K} \mathrm{m}^{2}\right)$ is the heat transfer coefficient on the air side of the membrane, $\delta(\mathrm{m})$ is the 252 thickness of the membrane and $\lambda_{e f f}(\mathrm{~W} / \mathrm{m} \mathrm{K})$ is the effective thermal conductivity of the 253 membrane obtained from [19]

$$
\lambda_{e f f}=\lambda_{v} \varepsilon+\lambda_{m}(1-\varepsilon)
$$

254 where $\lambda_{v}(0.0263 \mathrm{~W} / \mathrm{m} \mathrm{K})$ is the thermal conductivity in the membrane void space (air + water 255 vapor), and $\lambda_{m}(\mathrm{~W} / \mathrm{m} \mathrm{K})$ is the thermal conductivity of the membrane material (Table 1).

256 For a dual-layered membrane (membrane plus support) the effective thermal conductivity is 257 calculated as follows [14]: 


$$
\lambda_{\text {effd }}=\frac{\delta_{1}+\delta_{2}}{\frac{\delta_{1}}{\lambda_{\text {eff } 1}}+\frac{\delta_{2}}{\lambda_{\text {eff } 2}}}
$$

258 where $\delta_{1}(\mathrm{~m})$ is the thickness of the active layer and $\delta_{2}(\mathrm{~m})$ is the thickness of the membrane 259 support material. Since the support layer is considerably more porous than the active layer, $\lambda_{\text {eff } 2} \sim$ $260 \lambda_{v}$.

261 Values for the convective heat transfer coefficients in the permeate and brine-side boundary 262 layers, $h_{\mathrm{a}}$ and $h_{w}$, were calculated using the Chilton-Colburn analogy [14] in terms of the Nusselt 263 number,

$$
h=\frac{\lambda N u}{d_{h s}}
$$

264 For the calculation of $h_{w}\left(\mathrm{~W} / \mathrm{K} \mathrm{m}^{2}\right)$, the thermal conductivity of water $\left(\lambda_{w}\right)$ and the hydrodynamic 265 diameter of the feed side spacer were used. For the calculation of $h_{a}$, the thermal conductivity of 266 air $\left(\lambda_{v}\right)$ and the hydrodynamic diameter of the permeate-side spacer were used. The Nusselt 267 number was calculated from the correlation

$$
N u=k_{d c} 0.664 \operatorname{Re}^{0.5} \operatorname{Pr}^{0.33}\left(2 \frac{d_{h s}}{l_{m}}\right)^{0.5}
$$

268 where the Reynolds number was obtained from equation (19) and the Prandtl number was 269 obtained from

$$
\operatorname{Pr}=\frac{\mu_{v} C_{p}}{\lambda_{v}}
$$




\section{Results and Discussion}

276

277 The model was calibrated by comparing measured and predicted water production rates in 278 response to variation in brine temperature $\left(50<\mathrm{T}_{\mathrm{b} \text {,in }}<80{ }^{\circ} \mathrm{C}\right)$ (Figure 6). The temperature of the air going in the membrane module was ambient temperature $\left(\mathrm{T}_{\mathrm{a}, \mathrm{in}} \sim 25^{\circ} \mathrm{C}\right)$. For each membrane

280 type, membrane tortuosity was the sole fitting parameter (Table 1). It should be noted that for 281 all experiments, the amount vapor that is not condensed after the condenser is less than $10 \%$ of 282 the total amount of water produced.

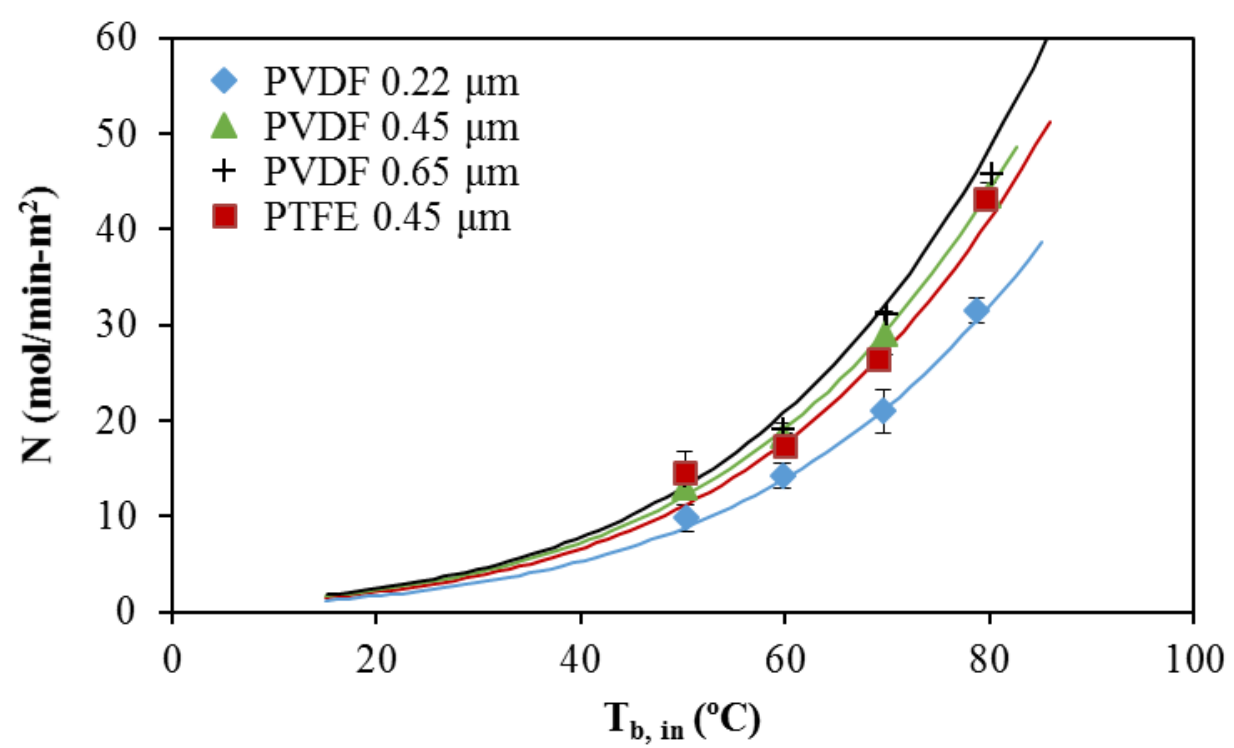

283 Figure 6. Relationship between inlet brine temperature and permeate molar flux. Data points represent experiments at influent brine temperatures from $50{ }^{\circ} \mathrm{C}$ to $80{ }^{\circ} \mathrm{C}, 0.05 \% \mathrm{NaCl}, \mathrm{u}_{\mathrm{a}}=9.5$ $\mathrm{m} / \mathrm{s}$ and $u_{\mathrm{b}}=0.11 \mathrm{~m} / \mathrm{s}$ that were used for model calibration. Points represent experimental data for membranes A (PVDF $\left.d_{p}=0.22 \mu \mathrm{m}, \tau=2.5\right)$, B (PVDF $\left.d_{p}=0.45 \mu \mathrm{m}, \tau=2\right)$ and $\mathbf{C}\left(\mathrm{PTFE} d_{p}\right.$ $=0.45 \mu \mathrm{m}, \tau=2.5)$ and $\mathbf{D}\left(\operatorname{PVDF} d_{p}=0.65 \mu \mathrm{m}, \tau=1.8\right)$. Solid lines represent model results. Error bars represent $+/$ - one standard deviation in the results of three repeat experiments at the conditions indicated.

Tortuosity values were selected to minimize the sum of squared error between the temperature- 
293 using data representing the rate of permeate production as a function of the sweep gas flow rate

294 and brine approach velocity for the four membrane types. Results (Figures 7 and 8) show that

295 SGMD performance can be simulated over a broad range of operational conditions and

296 membrane architectures, eliminating the need for a great many additional bench scale

297 experiments. In all experiments, permeate conductivity was $<20 \mu \mathrm{S} / \mathrm{cm}(<10 \mathrm{mg} / \mathrm{L} \mathrm{NaCl})$.

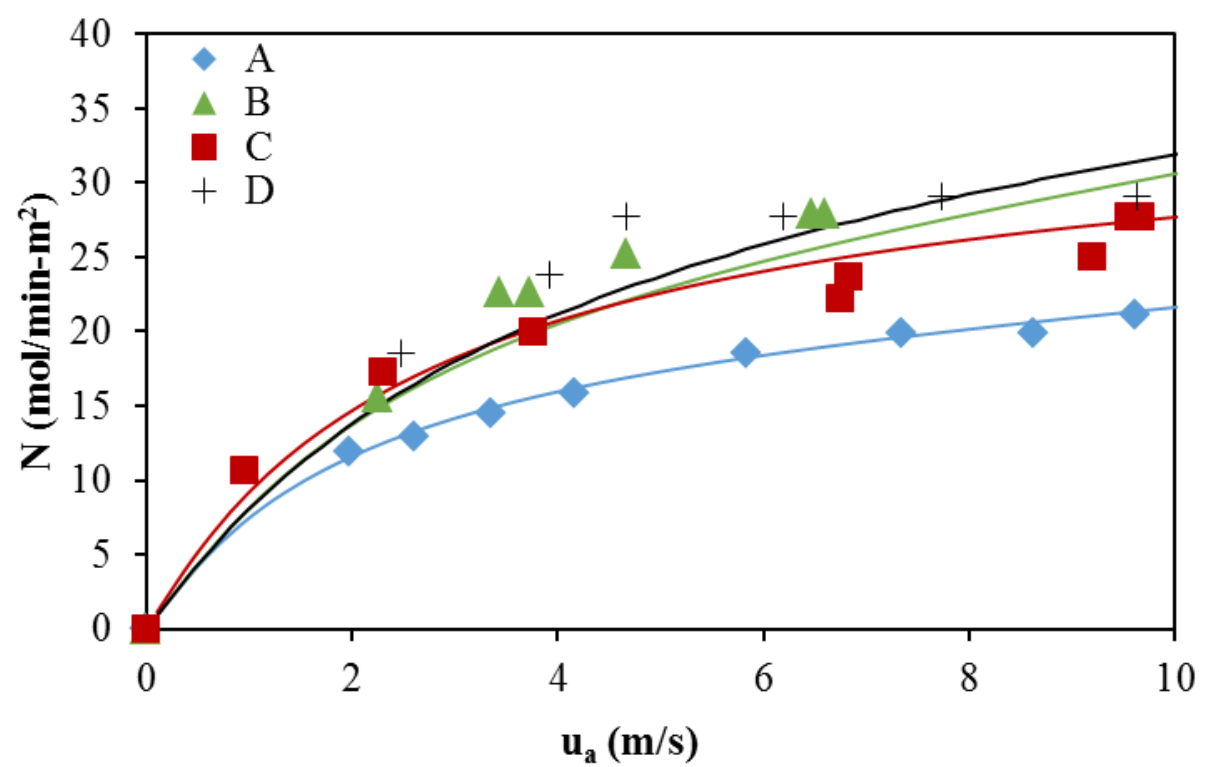

Figure 7. Dependence of permeate molar flux on the sweep air velocity at influent brine temperature $=70{ }^{\circ} \mathrm{C}$, salinity $=0.05 \% \mathrm{NaCl}$ and brine velocity $\mathrm{u}_{\mathrm{b}}=0.11 \mathrm{~m} / \mathrm{s}$. Points represent experimental data for membranes $\mathbf{A}\left(\operatorname{PVDF} d_{p}=0.22 \mu \mathrm{m}, \tau=2.5\right), \mathbf{B}\left(\mathrm{PVDF} d_{p}=0.45 \mu \mathrm{m}, \tau=\right.$ 2 ) and $\mathbf{C}\left(\operatorname{PTFE} d_{p}=0.45 \mu \mathrm{m}, \tau=2.5\right)$ and $\mathbf{D}\left(\operatorname{PVDF} d_{p}=0.65 \mu \mathrm{m}, \tau=1.8\right)$. Solid lines are 


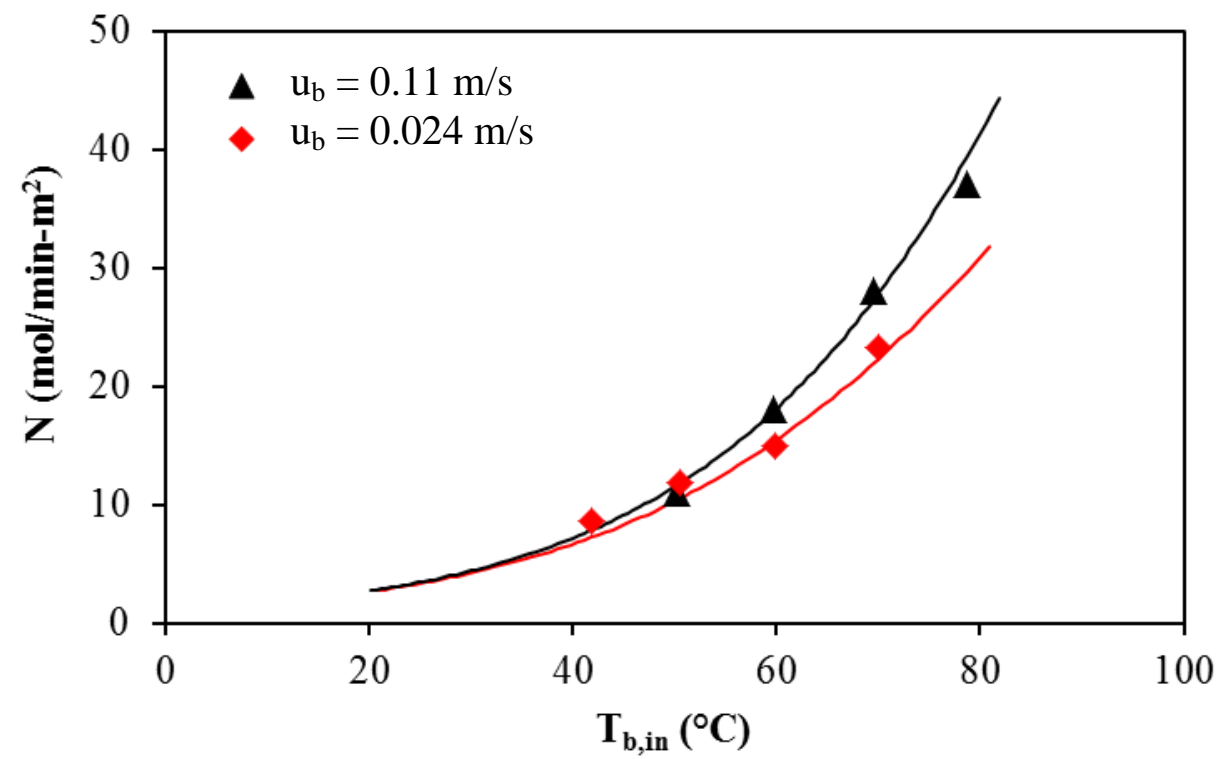

Figure 8. Effect of the brine flow rate and feed brine temperature on permeate molar flux for the PVDF membrane $\left(d_{p}=0.22 \mu \mathrm{m}\right)$ at a sweep air velocity of $9.5 \mathrm{~m} / \mathrm{s}$. Solid lines represent model predictions.

Heat transfer considerations.

311 It was originally hypothesized that water production was constrained by a combination of heat

312 and mass transfer limitations. Heat transfer to the brine/gas interface must continuously provide

313 the heat of vaporization at the observed/predicted rate of water purification plus any heat that is

314 transferred from the brine to the sweeping gas. The calculated difference between the bulk brine

315 and brine/air interfacial temperatures, or driving force for energy transfer to the liquid/gas

316 interface, is plotted as a function of position for three influent brine temperatures in Figure 9. 


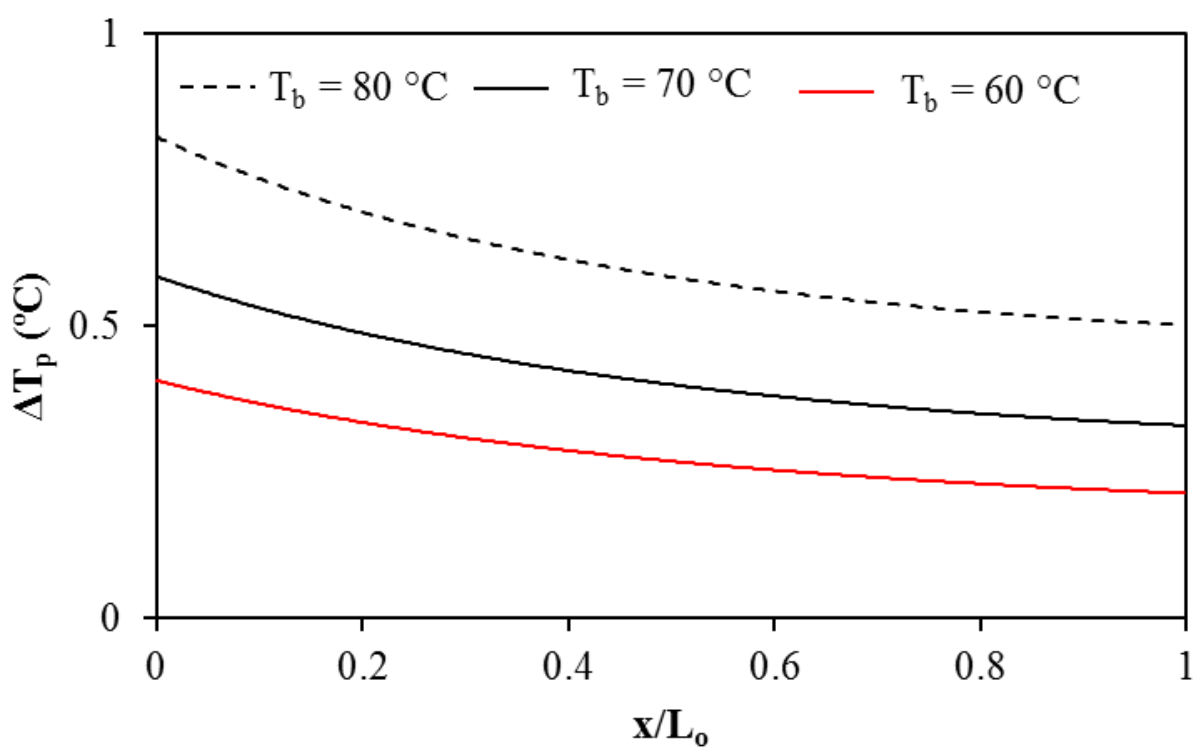

319 Figure 9. Temperature difference between the (bulk) brine and the membrane interface for three 320 influent brine temperatures as a function of dimensionless distance from the air entrance to the $321 \quad$ module; $u_{a}=9.5 \mathrm{~m} / \mathrm{s}$ and $u_{b}=0.11 \mathrm{~m} / \mathrm{s}$ for the PVDF $d_{p}=0.45 \mu \mathrm{m}$ membrane.

323 In each case, temperature differences were greatest at the brine exit (air entrance) of the module.

324 In addition to motivating the transfer of heat energy across the liquid phase boundary layer, the 325 temperature differences shown, reduce the temperature/vapor pressure at the brine/gas interface, 326 and thus the driving force for mass transfer through the membrane. The figure shows, however, 327 that most of the needed heat to support the observed evaporation rates can be provided with less 328 than a degree difference. Thus heat transfer does not provide a significant limitation to water 329 production under the operational conditions in these experiments. Heat transfer effects however, 330 remain important as determinants of simulated temperature profiles on the air and water sides of 331 the membrane.

332 For an experiment with inlet brine temperature $\mathrm{T}_{\mathrm{bi}}=80{ }^{\circ} \mathrm{C}, 87 \%$ of the energy transferred from 333 the brine to the membrane is used to evaporate the water and $13 \%$ is transferred across the 334 membrane/thermal boundary layer as sensible heat through conduction/convection. Energy 
335 losses to the environment were neglected without sacrificing agreement between simulated and

336 measured temperature profiles (data not shown).

337 Over the full range of conditions in these experiments, the calculated $\Delta \mathrm{T}_{\mathrm{p}}$ was $\leq 3.1{ }^{\circ} \mathrm{C}$,

338 reinforcing our assertion that heat transfer resistance within the thermal boundary layer was not a

339 major determinant of evaporation and water production rates. This assertion is also supported by

340 performance simulations in which the brine side spacer was eliminated (Figure 10). The figure

341 shows that elimination of the brine-side spacer, which increases brine-side resistance to heat

342 transfer, would have little consequence for the rate of water production. No such claim can be

343 made for the air-side spacer.

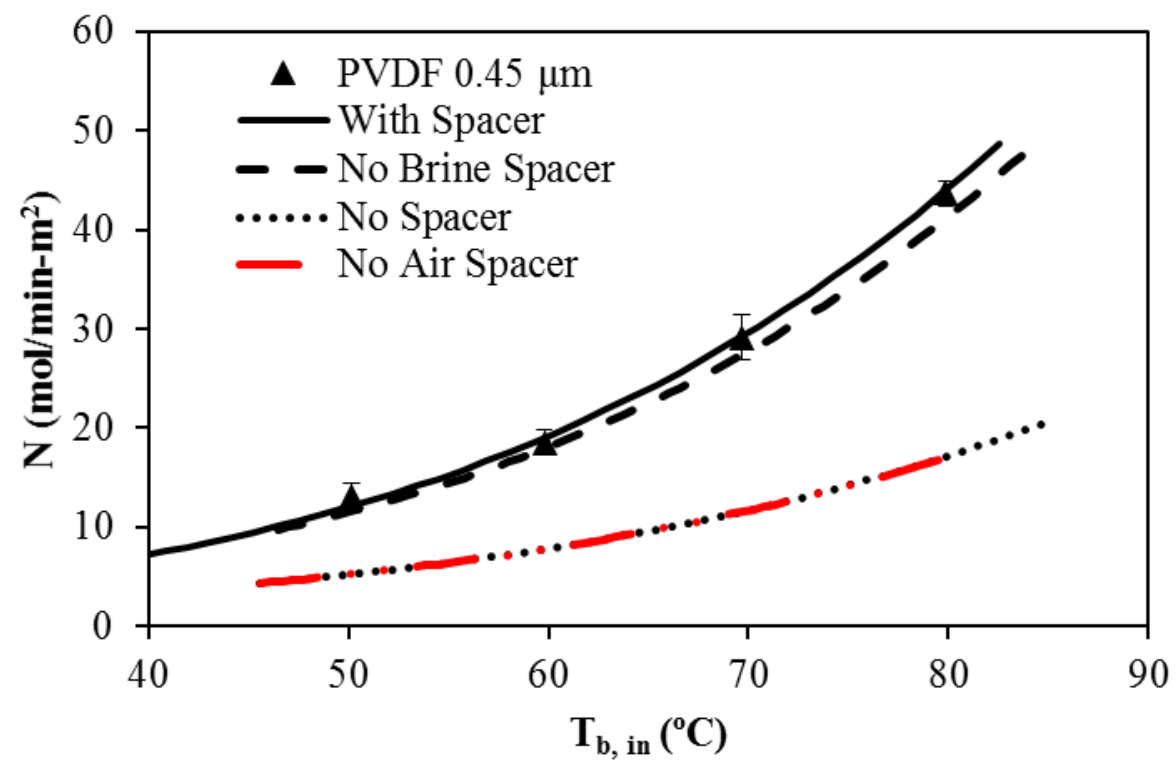

344 Figure 10. Effects of spacers on calculated water production for PVDF $d_{p}=0.45 \mu \mathrm{m}, \mathrm{u}_{\mathrm{a}}=9.5$ $345 \mathrm{~m} / \mathrm{s}$ and $u_{b}=0.11 \mathrm{~m} / \mathrm{s}$. Lines show results of simulations with spacers present on both sides of 346 the membrane, air-side spacer only, brine-side spacer only and no spacer present. Data were collected with both spacers present.

349 A large drop in brine temperature between the brine inlet and outlet would also limit module 350 performance. At the highest experimental temperature $\left(\mathrm{T}_{\mathrm{b}, \mathrm{in}}=80^{\circ} \mathrm{C}\right)$ and lowest brine flow rate 
$351\left(\mathrm{u}_{\mathrm{b}}=0.024 \mathrm{~m} / \mathrm{s}\right), \Delta \mathrm{T}_{\mathrm{p}}$ was about $4{ }^{\circ} \mathrm{C}$-again probably not enough to present a significant

352 limitation to water production. Nevertheless, practical MD module designs that involve

353 significantly larger in-module travel distance and longer brine retention times should consider

354 the relationship between brine flow and temperature drop in order to maintain the brine vapor

355 pressure over the entire length of the module.

356 It follows that rates of water production were largely limited by mass transfer, i.e., by (i)

357 resistance to mass transport in the membrane, (ii) in the gas-phase boundary layer, (iii) near-

358 saturation of the gas stream with water vapor ahead of the module exit, or (iv) some combination

359 of these. To eliminate effects due to accumulation of water vapor in the gas stream over the

360 length of the module, simulations were conducted in which water transfer rates were calculated

361 while constraining the gas-phase concentration of water vapor to zero (curve labeled $\mathrm{P}_{\mathrm{w}}=0$ in

362 Figure 11).

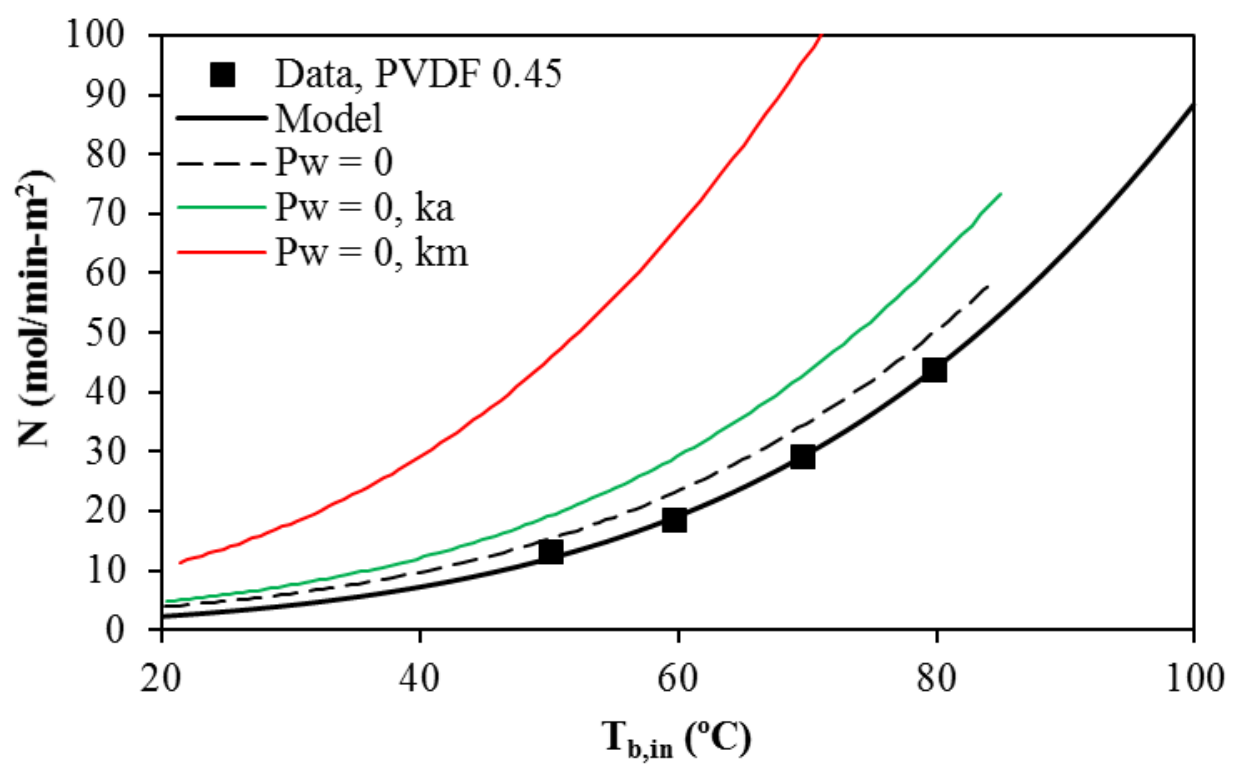

363 Figure 11. Results of simulations in which the effect of accumulation of water vapor in the air 364 flow was eliminated (by setting $\mathrm{P}_{\mathrm{w}}=0$ ). In subsets of these simulations, either the air-side 365 boundary layer resistance $\left(1 / \mathrm{k}_{\mathrm{a}}\right)$ or membrane resistance $\left(1 / \mathrm{k}_{\mathrm{m}}\right)$ was minimized. All calculations 366 involved the 0.45 micron PVDF membrane. 
368 Under those circumstances, there was very little increase in the predicted water purification rate

369 when water vapor on the air side was eliminated, indicating that saturation effects were not the 370 primary source of rate limitation (Figure 11).

371 The remaining constraints on water production include only membrane and air-side resistances to

372 mass transfer. To separate these effects, each resistance was individually eliminated (separately)

373 in subsequent simulations. Results (Figure 11) indicate that the membrane resistance is the

374 primary source of water purification rate limitation in these experiments. This effect would be

375 more pronounced for membranes with greater thickness or smaller pore size.

377 Membrane/Module Physical Characteristics.

378 Brine- and gas-phase spacers potentially affect water production rates (Figure 10). Brine side 379 spacers increase the heat transfer coefficient and on the brine side of the membrane, enhancing 380 heat transfer to the brine/gas interface. The permeate-side spacer reduces boundary layer 381 resistance to both heat and mass transfer. As mentioned above, results of simulations indicate 382 that the brine-side spacer is of little relevance to water production-i.e., that compression of the 383 brine-side thermal boundary layer with consequent reduction of heat transfer resistance does not 384 increase water production. It follows that resistance to heat transfer from the bulk fluid to 385 interface does not effectively impede the process, and liquid-phase resistance to heat transfer will 386 receive no further consideration here. Similarly, the resistance to mass transfer provide by the 387 air-side boundary layer, although significant under some circumstances, will not be discussed in 388 great detail. 
389 Membrane characteristics that affect mass transfer are primarily the lumped parameter $\varepsilon / \tau \delta$ and

$390 \mathrm{~d}_{\mathrm{p}}$. The interdependence of membrane structural parameters and operational variables further

391 illustrates the importance of simulations in determining the limits of module performance. Here

392 the co-dependence of water production rates on $\varepsilon / \tau \delta$ or $d_{p}$ (structural parameters) and sweep gas

393 or brine flow velocities (operational variables) is illustrated in a series of contour plots (Figures

394 12-14) built from calculations with the model. Values used for the independent variables in these

395 plots comprise the range of membrane characteristics and operating conditions of the 396 experimental work.

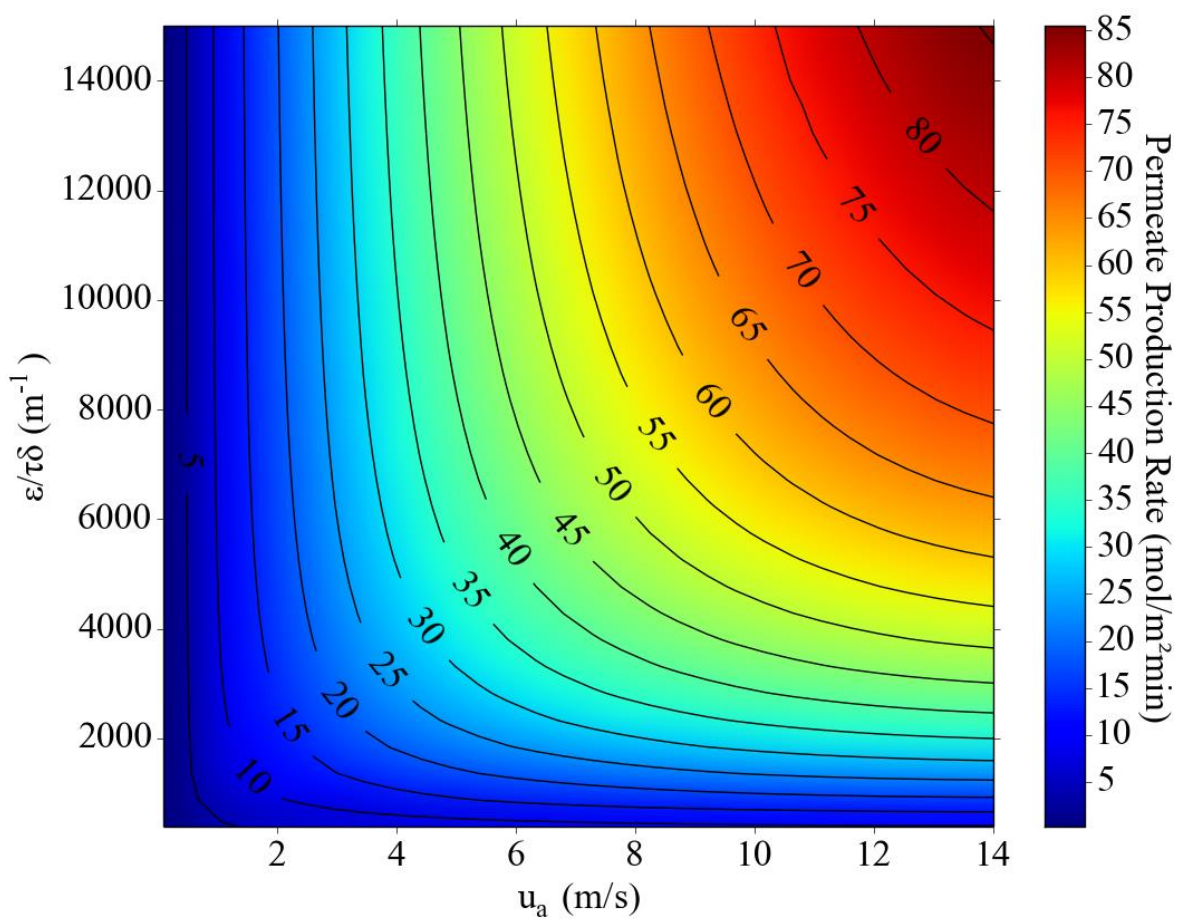

397 Figure 12. Calculated permeate production flux as a function of sweeping gas velocity and the 398 ratio of membrane porosity to tortuosity times thickness, for $u_{b}=0.11 \mathrm{~m} / \mathrm{s}$ and brine inlet temperature of $\mathrm{T}=70^{\circ} \mathrm{C}$. Membrane pore size was $\mathrm{d}_{\mathrm{p}}=0.45 \mu \mathrm{m}$.

400

401 For the single-layer membranes, for example, water production is sensitive to $\mathrm{u}_{\mathrm{a}}$ at high values of $402 \varepsilon / \tau \delta$ (or $\mathrm{d}_{\mathrm{p}}$ ) and low sweep gas velocities (Figures 12 and 13). In that region, resistance to 
convective transport through the gas-phase boundary layer dominates the overall resistance to

404 mass transport, potentially accounting for the observed relationship. Alternately, the exiting gas

405 stream could approach saturation ahead of the module exit, in which case the water production

406 rate would increase with gas flow rate. As previously shown (Figure 11), for the length of

407 membrane module used in this study, saturation of the gas stream was not the primary source of

408 limitation to water production. If a longer or hollow fiber membrane module were used,

409 however, saturation of the gas stream might limit the water purification rate.

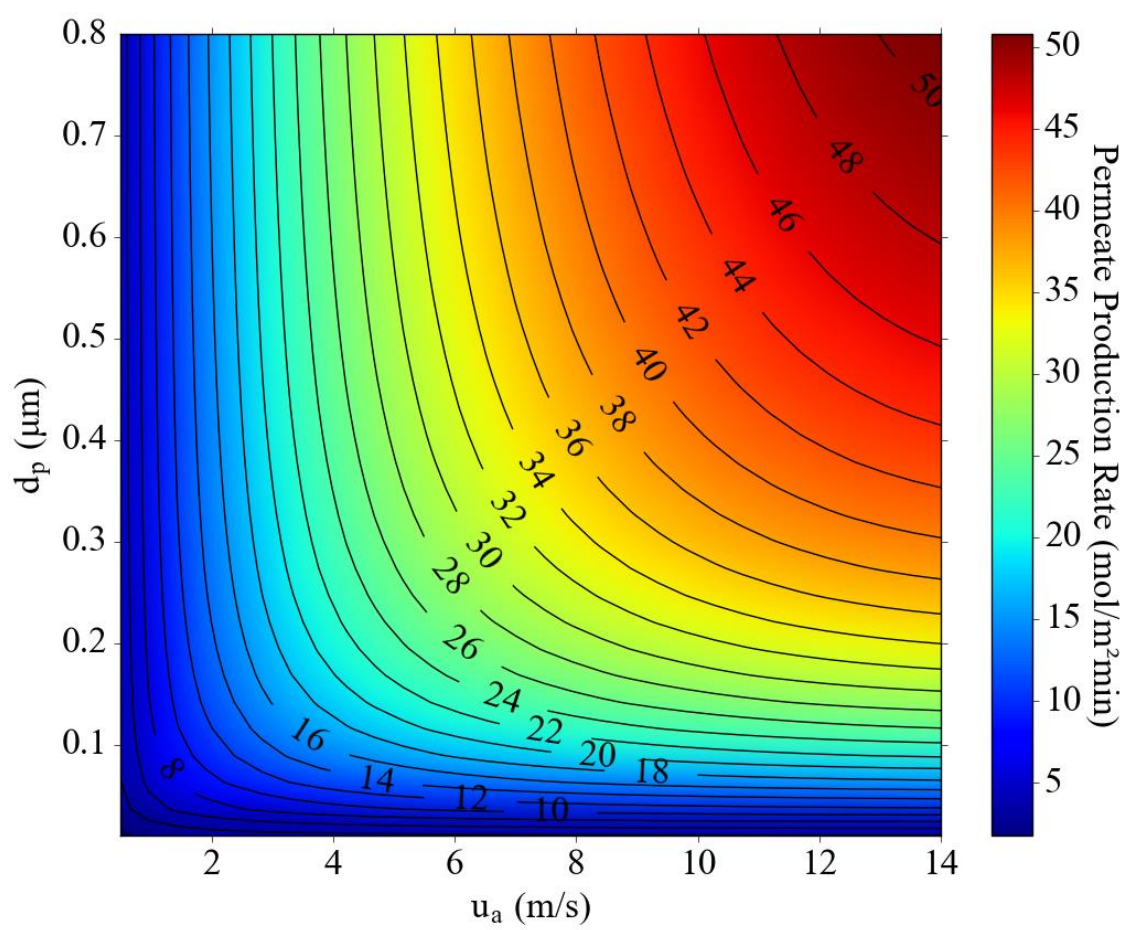

$410 \quad$ Figure 13. Calculated permeate production flux as a function of membrane pore size and 411 sweeping gas velocity with $\mathrm{u}_{\mathrm{b}}=0.11 \mathrm{~m} / \mathrm{s}$, brine inlet temperature of $\mathrm{T}=70^{\circ} \mathrm{C}$ and $\varepsilon / \tau \delta=3000$.

413 At $\mathrm{T}=70{ }^{\circ} \mathrm{C} ; \mathrm{u}_{\mathrm{a}}=9.5 \mathrm{~m} / \mathrm{s} ; \mathrm{u}_{\mathrm{b}}=0.11 \mathrm{~m} / \mathrm{s}$, water production was sensitive to membrane pore size 414 and the lumped parameter $\varepsilon / \tau \delta$. The relationship is particularly acute at low values of $\varepsilon / \tau \delta$ or $d_{p}$ 415 (Figures 13 and 14), for which membrane resistance tends to restrict water purification rates. 
416 Brine velocity is an important determinant of water production only brine approach velocities are

417 low and $\varepsilon / \tau \delta$ is high (which implies low membrane resistance) (Figure 14). The result would be

418 expected if high permeate flux and long brine retention times result in significant cooling of the

419 brine before it exits the module. Large membrane pore size, which also lowers membrane

420 resistance to mass transfer, should have a similar effect.

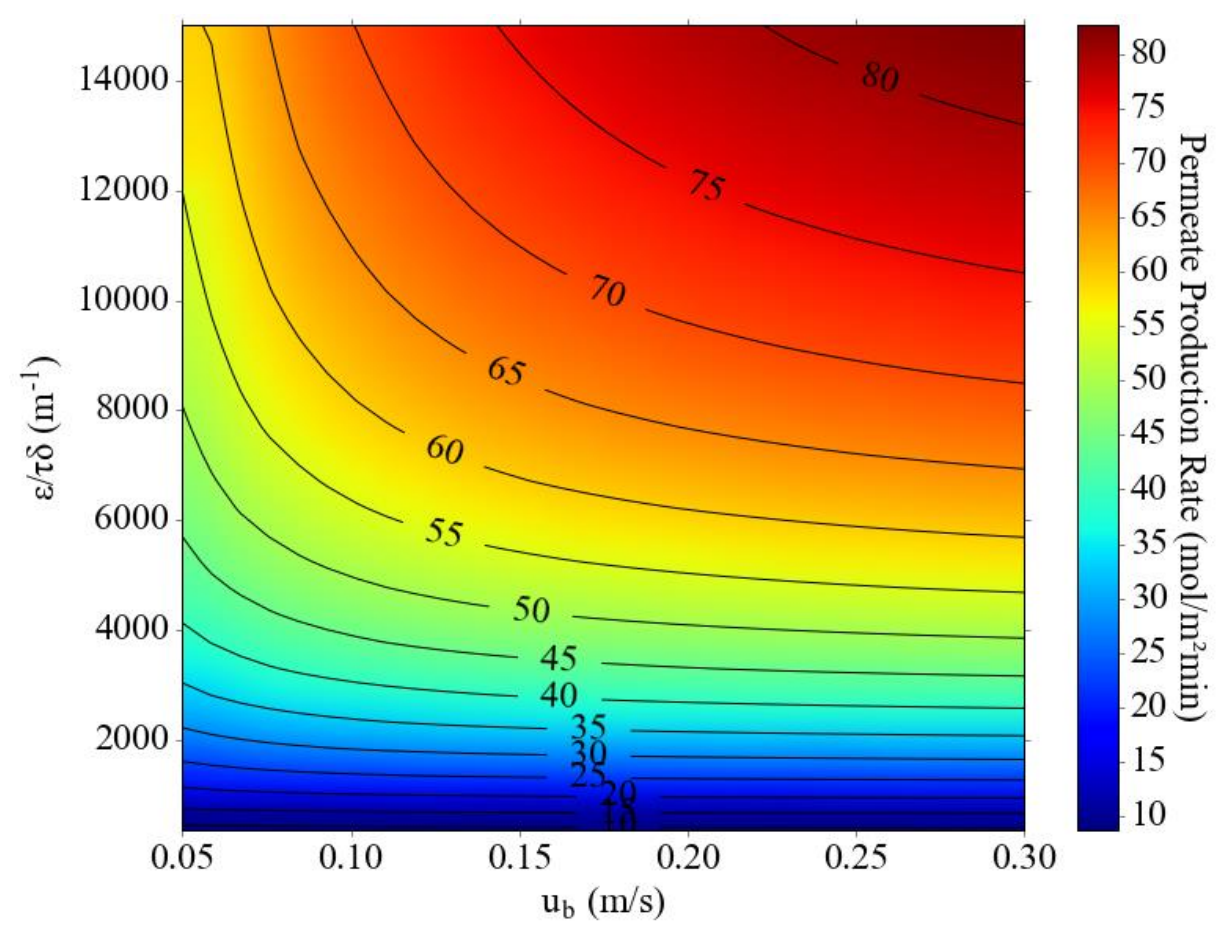

421 Figure 14. Calculated permeate production flux as a function of brine velocity and the ratio of membrane porosity to tortuosity times thickness with $u_{a}=9.5 \mathrm{~m} / \mathrm{s}$ and brine inlet temperature of $\mathrm{T}=70^{\circ} \mathrm{C}$. Membrane pore size was $\mathrm{d}_{\mathrm{p}}=0.45 \mu \mathrm{m}$.

426 as a function of pore diameter and sweep gas velocity (other operating conditions fixed) in

427 Figure 15. At effective pore diameters $<0.3 \mu \mathrm{m}$, the effect of Knudsen resistance is readily 428 apparent. At larger pore diameters, the Knudsen contribution is much reduced, and intra429 membrane molecular diffusion becomes more important as a source of overall resistance to mass 430 transfer. At the higher pore diameters, the resistance ratio is fairly sensitive to sweep gas 
431 velocities at $u_{a}<4 \mathrm{~m} / \mathrm{s}$, where boundary layer resistance is relatively large, but sensitivity

432 decreases at higher velocities.

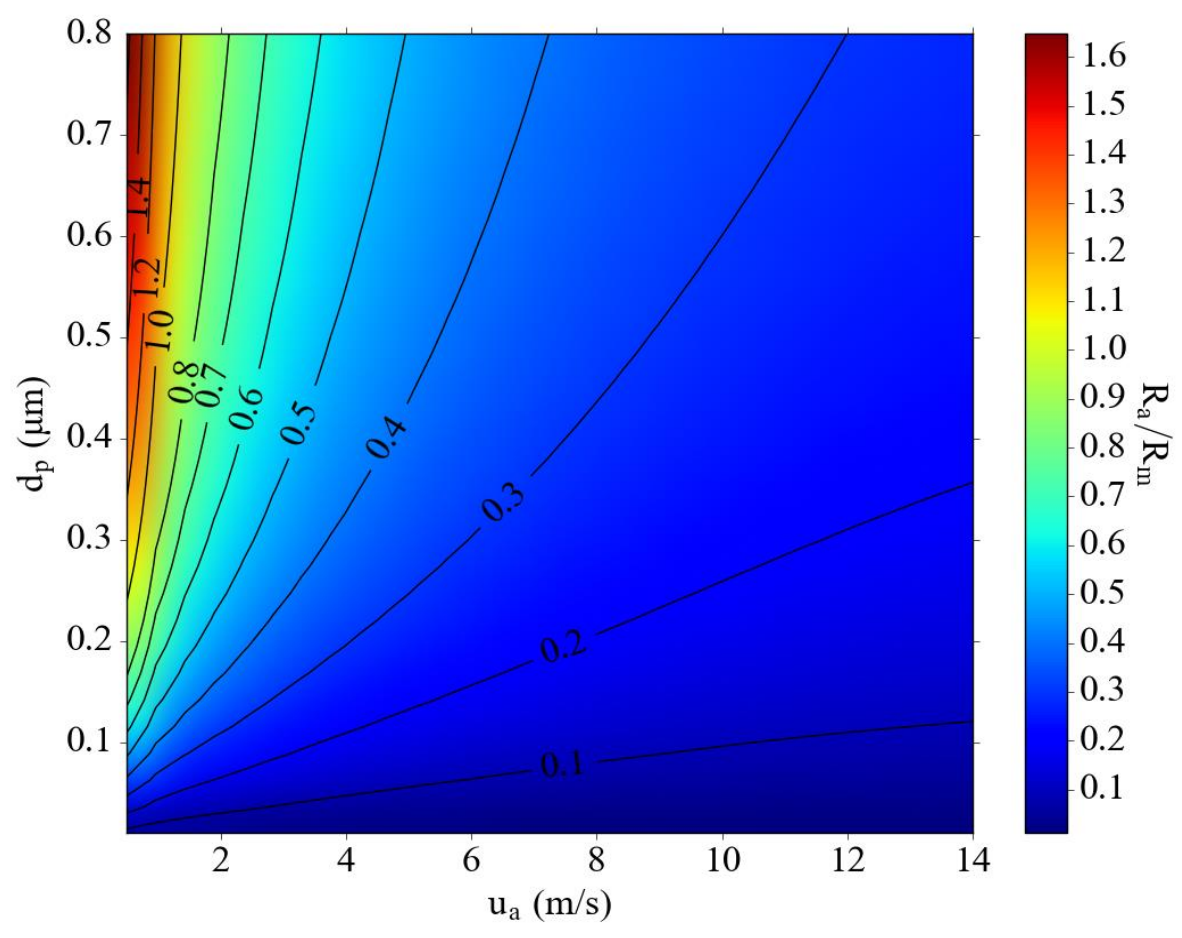

433 Figure 15. Mass transfer resistance ratio of the air boundary layer to membrane as a function of sweeping gas velocity and membrane pore diameter with $\mathrm{u}_{\mathrm{b}}=0.11 \mathrm{~m} / \mathrm{s}$ and brine inlet temperature of $\mathrm{T}=70{ }^{\circ} \mathrm{C}$.

438 Coupled heat and mass balances were used to predict permeate production during SGMD in a

439 flat sheet module for four different membranes. Calibration was based on a single fitted 440 parameter - the membrane tortuosity. The calibrated model was valid over a wide range of feed 441 water temperatures, feed water flow rates, and sweep gas velocities. The validated model was 442 then used to predict water production rates as a function of both operational variables and 443 membrane characteristics. For the range of operating conditions in the study, performance 444 simulations suggest that water purification rates were limited primarily by the membrane 445 resistance to mass transfer, as opposed to resistance to mass transfer in the air-side boundary 
446 layer, the accumulation of water vapor in the sweep gas, or heat transfer considerations. The 447 importance of MD simulations in identifying sources of performance limits is readily apparent 448 from the results presented. It is also important to note that results of this work cannot be 449 extended to practical membrane modules of vastly different dimension or type without model 450 reconfiguration and reapplication. 


\section{Abbreviations}

\begin{tabular}{|l|l|l|}
\hline $\mathrm{A}_{\mathrm{i}}$ & $\begin{array}{l}\text { Surface area over a length of a section of the } \\
\text { module }\end{array}$ & $\mathrm{m}^{2}$ \\
\hline $\mathrm{c}_{\mathrm{p}}$ & Heat capacity & $\mathrm{J} / \mathrm{mol} \mathrm{K}$ \\
\hline $\mathrm{d}$ & Diameter & $\mathrm{m}$ \\
\hline $\mathrm{d}_{\mathrm{f}}$ & Diameter of spacer filament & $\mathrm{m}$ \\
\hline $\mathrm{d}_{\mathrm{hs}}$ & Hydrodynamic diameter & $\mathrm{m}$ \\
\hline $\mathrm{d}_{\mathrm{p}}$ & Pore diameter & $\mathrm{m}$ \\
\hline $\mathrm{D}$ & Diffusivity & $\mathrm{m}^{2} / \mathrm{s}$ \\
\hline $\mathrm{h}$ & Heat transfer coefficient & $\mathrm{W} / \mathrm{K} \mathrm{m}{ }^{2}$ \\
\hline $\mathrm{H}$ & Spacer thickness & $\mathrm{m}$ \\
\hline$\Delta \mathrm{Hv}$ & Latent heat of vaporization & $\mathrm{J} / \mathrm{kg}$ \\
\hline $\mathrm{J}$ & Water vapor flux & $\mathrm{mol} / \mathrm{m}^{2} \mathrm{~min}$ \\
\hline $\mathrm{k}$ & Mass transfer coefficient & $\mathrm{m} / \mathrm{s}$ \\
\hline $\mathrm{Kn}$ & Knudsen number & \\
\hline $\mathrm{k}_{\mathrm{dc}}$ & Correction factor for spacer geometry & \\
\hline $\mathrm{L}$ & Membrane length & $\mathrm{m}$ \\
\hline $\mathrm{Le}$ & Lewis number & \\
\hline $\mathrm{l}_{\mathrm{m}}$ & Spacer mesh length & $\mathrm{m}$ \\
\hline $\mathrm{m}$ & Molecular weight & $\mathrm{kg} / \mathrm{mol}$ \\
\hline$\dot{\mathrm{n}}$ & Molar flow & $\mathrm{mol} / \mathrm{min}$ \\
\hline $\mathrm{Nu}$ & Nusselt number & \\
\hline $\mathrm{P}$ & Pressure & $\mathrm{Pa}$ \\
\hline $\mathrm{Pr}$ & Prandtl number & \\
\hline $\mathrm{q}$ & Volumetric flow & $\mathrm{L} / \mathrm{min}$ \\
\hline $\mathrm{Q}$ & Thermal content & $\mathrm{J}$ \\
\hline $\mathrm{r}$ & Radius & $\mathrm{m}$ \\
\hline $\mathrm{R}$ & Resistance & \\
\hline $\mathrm{Re}$ & Reynolds number & $\mathrm{K}$ \\
\hline $\mathrm{Sc}$ & Schmidt number & $\mathrm{m}$ \\
\hline $\mathrm{Sh}$ & Sherwood number & $\mathrm{Unitless}$ \\
\hline $\mathrm{T}$ & Temperature & \\
\hline $\mathrm{Z}$ & Unitless length & \\
\hline $\mathrm{Greek} \mathrm{Symbols}$ & Thickness of membrane & \\
\hline$\delta$ & Vapor flow & \\
\hline$\Delta \dot{\mathrm{n}}$ & Porosity & \\
\hline$\varepsilon$ & & \\
\hline & & \\
\hline
\end{tabular}




\begin{tabular}{|l|l|l|}
\hline$\theta$ & Spacer mesh angle & degrees \\
\hline$\lambda$ & Thermal conductivity of fluid & $\mathrm{W} / \mathrm{m} \mathrm{K}$ \\
\hline$\mu$ & Dynamic viscosity & $\mathrm{kg} / \mathrm{m} \mathrm{s}$ \\
\hline$\rho$ & Density & $\mathrm{kg} / \mathrm{m}^{3}$ \\
\hline$\tau$ & Tortuosity & Unitless \\
\hline$\varphi$ & voidage & Unitless \\
\hline$\nu$ & Kinematic viscocity & $\mathrm{m}^{2} / \mathrm{s}$ \\
\hline
\end{tabular}

\begin{tabular}{|l|l|}
\hline \multicolumn{2}{|l}{ Subscripts } \\
\hline 1 & membrane first layer, active \\
\hline 2 & membrane second layer, support \\
\hline a & Air \\
\hline b & Brine \\
\hline c & Condensation \\
\hline e & Evaporation \\
\hline f & filament \\
\hline eff & Effective single layer membrane \\
\hline effd & Effective for dual layer membrane \\
\hline Kn & Knudsen \\
\hline m & Membrane \\
\hline mol & Molecular \\
\hline p & Pore \\
\hline tot & total \\
\hline $\mathrm{v}$ & Vapor \\
\hline w & Water \\
\hline
\end{tabular}




\section{Acknowledgments}

This work was supported by grants from the US Bureau of Reclamation, the Salt River Project, and the Water, Environmental, and Energy Solutions Program (University of Arizona). Content is solely the responsibility of the authors and does not necessarily represent the official views of any supporting organization. The authors wish to acknowledge Jamie Vail Salebra and Tate Tolson for their contributions during data collection. 


\section{References}

[1] K. Smolders, A.C.M. Franken, Terminology for Membrane Distillation, Desalination Desalination, 72 (1989) 249-262.

[2] E. Curcio, E. Drioli, Membrane distillation and related operations - A review, Sep. Purif. Rev., 34 (2005) 35-86.

[3] L. Peña, J.M. de Zárate, J.I. Ortiz Mengual, Steady states in membrane distillation: influence of membrane wetting, Journal of the Chemical Society, Faraday Transactions, 89 (1993) 43334338.

[4] M. Khayet, S.M. Takeshi, Membrane distillation principles and applications, in, Elsevier, Amsterdam; Boston, 2011.

[5] K. Schneider, W. Hölz, R. Wollbeck, S. Ripperger, Membranes and modules for transmembrane distillation, Journal of Membrane Science, 39 (1988) 25-42.

[6] K.W. Lawson, D.R. Lloyd, Membrane distillation, Journal of Membrane Science, 124 (1997) $1-25$.

[7] K. Charfi, M. Khayet, M.J. Safi, Numerical simulation and experimental studies on heat and mass transfer using sweeping gas membrane distillation, Desalination, 259 (2010) 84-96.

[8] M. García-Payo, C. Rivier, I. Marison, U. Von Stockar, Separation of binary mixtures by thermostatic sweeping gas membrane distillation: II. Experimental results with aqueous formic acid solutions, Journal of Membrane Science, 198 (2002) 197-210.

[9] M. Khayet, M.P. Godino, J.I. Mengual, Possibility of nuclear desalination through various membrane distillation configurations: a comparative study, International Journal of Nuclear Desalination, 1 (2003) 30-46.

[10] M. Khayet, P. Godino, J.I. Mengual, Theory and experiments on sweeping gas membrane distillation, Journal of Membrane Science, 165 (2000) 261-272.

[11] V. Karanikola, A.F. Corral, H. Jiang, A. Eduardo Sáez, W.P. Ela, R.G. Arnold, Sweeping gas membrane distillation: Numerical simulation of mass and heat transfer in a hollow fiber membrane module, Journal of Membrane Science, 483 (2015) 15-24.

[12] M. Khayet, Membranes and theoretical modeling of membrane distillation: A review, Advances in Colloid and Interface Science, 164 (2011) 56-88.

[13] M. Khayet, L. Pena, J. Mengual, Utilisation of Sweeping Gas Membrane Distillation Module to Improve the Performance of One Stage Multieffect Distiller, in: Anales de Fisica, Spanish Royal Society of Physics, 1999, pp. 169-177.

[14] L.Z. Zhang, Heat and mass transfer in a randomly packed hollow fiber membrane module: A fractal model approach, International Journal of Heat and Mass Transfer, 54 (2011) 29212931.

[15] T.K. Sherwood, R.L. Pigford, Absorption and extraction, McGraw-Hill, New York 1952.

[16] K.W. Lawson, D.R. Lloyd, Membrane distillation .1. Module design and performance evaluation using vacuum membrane distillation, Journal of Membrane Science, 120 (1996) 111121.

[17] A.R. Da Costa, A.G. Fane, D.E. Wiley, Spacer characterization and pressure drop modelling in spacer-filled channels for ultrafiltration, Journal of Membrane Science, 87 (1994) 79-98.

[18] H. Grober, S. Erk, U. Grigull, Fundamentals of heat transfer, McGraw-Hill, New York, 1961. 
[19] A.K. Datta, Porous media approaches to studying simultaneous heat and mass transfer in food processes. I: Problem formulations, Journal of Food Engineering, 80 (2007) 80-95. 